\title{
Web design structure with wordpress content management for sports centre booking system
}

\author{
Nor Sajidah Ab Ghani, Murizah Kassim, Aziati Husna Awang \\ Faculty of Electrical Engineering, Universiti Teknologi MARA, Malaysia
}

\begin{tabular}{l}
\hline \hline Article Info \\
\hline Article history: \\
Received Jan 11, 2020 \\
Revised Mar 13, 2020 \\
Accepted Apr 1, 2020 \\
\hline
\end{tabular}

\section{Keywords:}

Booking system

Content management

Web design

Web structure

WordPress

\begin{abstract}
Sports center booking system need to be more systematic to increase its efficiency. The World Wide Web (WWW) had been a revolution and it has been utilized to be tools of automation in many applications, including managing booking and payment system in this area of services. However, existing sport facilities system faced difficulties in facilities maintenance especially for ID booking system to Court Centre and does not delegate any confirmation to users on their booking. This paper aims at integrating stripe payment method by using the WordPress platform where it is one of the content management system (CMS) by using XAMPP. MySQL has been used to store the database while PHP and HTML have been designed to generate $\mathrm{QR}$ code. A hierarchical web structure was designed, and the system designed is based on new member, staffs, and students needed functionality. The new members need to register and pay their members fees. Existing student and staff need to sign in using their ID Number. This system has provided a booking system which presented the availability of time and date as well as the payment for the new members. Upon booking and payment, email and QR code are given to the user after the confirmation booking by an administrator. The result shows the model of web design structure and the increase of efficiency after implementing the new features on the web system which shows $86.66 \%$ of increases in term of using the website to book the facilities at the Sports Centre from the existing system.
\end{abstract}

Copyright $\odot 2020$ Institute of Advanced Engineering and Science. All rights reserved.

\section{Corresponding Author:}

Murizah Kassim,

Faculty of Electrical Engineering,

Universiti Teknologi MARA, 40450 UiTM Shah Alam, Selangor, Malaysia.

Email: murizah@uitm.edu.my

\section{INTRODUCTION}

In this explosion of digital era, World Wide Web (WWW) has revolutionized the usage of computer and the internet. The WWW is a system of online substance arranged in HTML and accessed via HTTP. Originally WWW was designed by a contractor at CERN in 1991. A sharp increase of internet users could be seen from 2002 until now [1]. The World at Your Fingers phrase has indicated that the users can get information and internet utilizing PCs and cell phone whenever and anyplace without time restriction. Other than that, the impact from this WWW revolution can be seen in the increment of web-based application development [2]. Today, most of organizations and agencies have computerized the daily operation system. One of it is the booking system, which has evolved into one of the famous business today. The booking system is a computerized system used to store and save information and conduct communications such as air travel, hotel, car rental, and others. Today, people can book anytime or anywhere if they want to buy a ticket or reserved a place. This user-friendly feature is improved the company business management and profit. The advancement of technology has led to big progress in booking system over the years. Three important criteria have been reviewed on the existing system that related to web structure development included in the campus which are campus sports facilities [3], smart campus [4], 2017 and iBook Court [5]. 
Monitoring System for Campus Sports Facilities has been developed such as using Radio-frequency identification (RFID) scanner to generate the database user and design web application using Microsoft's Visual Studio 2015[6]. RFID was used to store information, track and electronic identification which were called an automated data-capture (ADC) technology [7]. Nevertheless, this application is good because they have a QR code for the user to see how to play the game properly. Even though RFID was one of the latest technologies, it was not compatible with multiusers consisting of the students, staffs, and normal users. The students and staffs have the unique university Identity, Card (ID) however, normal non-university users who had just become members did not have that unique university ID which is used to book the sports facilities. The drawback of the existing system is the payment for the fees is not provided in the previous system. However, this application is limited only for badminton court where it is limit to the users who were onsite at badminton court only. Today, most smart campus used contactless technology method to access the smart campus facilities. Most embedded wireless, Internet of Things (IoT), LoRaWan communication between the device and another where it could operate within long or short distances [8]. RFID are mostly used to save data small memory card and reload the money for payment. This system is good to be used for booking system, because the users can use their smartphone to book the place, pay the fees or check detail about their booking. iBook Court was the web-based application which used for the online reservation for the court from different companies. The user could choose and compare the company who provided different facilities and price for the rent. The application had two participants where the system administrator and a normal user. The functionality that had been provided for normal use such as online court reservation, email confirmation, online payment for reservation, compare the best facilities and open competition to challenge other players. On top of that, the system administrator can perform various functions like manage members by performing register, send an email confirmation, set up the competition, generate reports on payment, reservation statistics and the usage of the facilities and can collaborate with another company. The system was $100 \%$ preferred by the users because they could choose and compare the best facilities and price. Besides, they could also open for competitions that were good for them to show their skills and learn new skills in competitions. However, this system was not suitable for the campus because the facilities were limited and comparison with other companies is not a necessity.

Content management system (CMS) is a web application designed to modify the website's content where the interface allows users to have full control $[9,10]$. The users could design the website even they were not familiar to Hyper Markup Language (HTML). The CMS helped to build website faster as well as save the money and time. Therefore many studies show that CMS was the most popular platform to design the web for e-commerce, and blogs [11]. There were several platforms in CMS which most popular among the users such as WordPress, Joomla, and Drupal. WordPress is graded about 32.7\% of all websites had been powered by WordPress compared to the other platforms such as Joomla and Drupal. WordPress was the most popular among the user. Besides, WordPress is free and distributed under the GNU General Public License [12]. Moreover, WordPress is a mature platform that used technology like PHP and SQL and JavaScript that meet the strict International Coding Statement set by W3C (World Wide Web Consortium). Other than that, WordPress had 2570 themes and 31435 number of plug-ins more than other platforms. It gives advantages to users by having more choices and flexibility to build a homepage. However, WordPress has less security than other platforms, but WordPress has a smaller number of sensitive directories and files which cannot directly be hacked. The most important thing before designing the website is the structure of the page on the website. This is because the success of the website page is based on the information architecture matcher and the user expectation [13]. The structure of a website is determined by the design of the navigation within the website [14]. There were four types of structures: a linear structure, hierarchical structure, web structure, and hierarchical structure. Figure 1 shows how linear structure links on a website. Sequentially the user navigated, moving from one page to another page. Information flowing as a narrative, a timeline or in a logical order was ideal for sequential processing. However, a simple sequential organization usually only worked for smaller sites. Showed how the linear structure worked. Figure 2 below showed how the hierarchical structure works. A hierarchical navigation structure was in its nature resembles a tree. The homepage was upstairs while at the below part, it was divided into categories that could be further divided into different sub-categories. Usually, there was a link to the homepage on each page below. Figure 3 shows web structures where the browsing structure allowed users to track their information flow-it could be unique for every user using the application [15]. There are many links between the different pages to make good web crawling as mentioned [16]. Some webpages have limited its utilities for larger sites with more pages. Figure 4 shows a composite navigation structure that integrated and the least limited in various aspects of the other structures. Some of it could be linear or hierarchical and was especially useful where the multimedia product had many topics and subtopics. Users could navigate freely (web) but the pairs were linked into parts of the website hierarchically or linearly. 


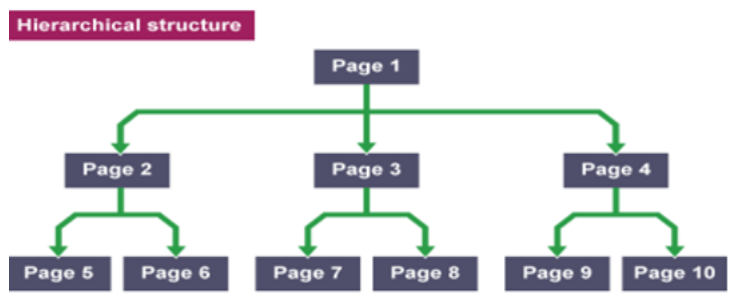

Figure 1. Linear structure

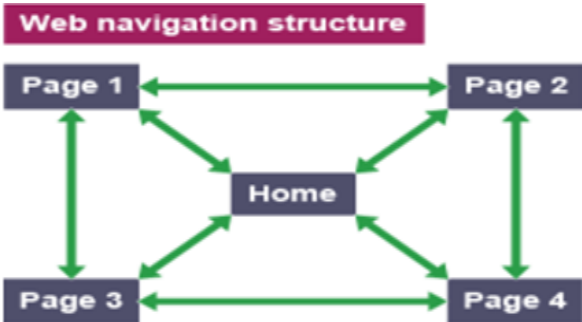

Figure 3. Web structure
Figure 2. Hierarchical structure

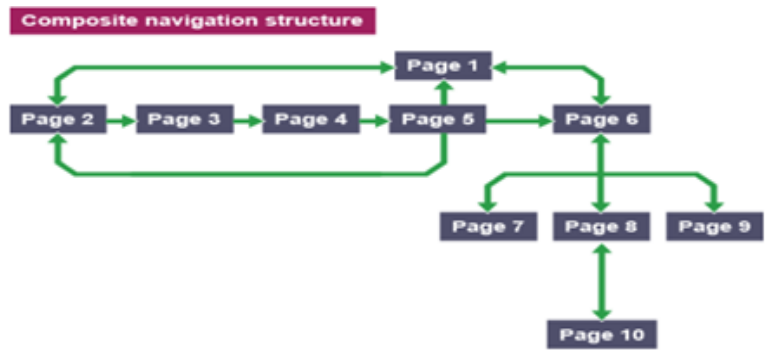

Figure 4. Composite structure

Due to increasing spread of internet banking, booking online and shopping online, the online payment system was skyrocketing in the recent decade mostly in resort reservations [17] that facilitated better service [18]. As the world progress further with the development of technology, online payment systems were growing [19]. As these increased the improvement and provision, they were also increased secure online payment transitions, so the percentage of cheque and cash transactions would decrease. An online payment system is a way to make transactions or pay for goods and services via an electronic medium [20]. Credit and debit cards are among the most popular online payment forms. Alternative payment methods are also available, such as bank transfers, electronic wallets, smart cards or bitcoin wallets. Credit and cash payment systems could be classified into two, which are credit payment system and cash payment system. Credit payment System using credit card was a form of e-payment system that required the use of card issued to the cardholder by the financial institution for online. Besides that, e-wallet is a form of prepaid account that stores financial information for users such as debit and credit card information to facilitate the online transaction. Cash payment system is a direct debit financial system in which the account holder ordered the bank to collect electronically a certain amount of money from his account to pay for services which is todays trend and model of paymentment in business [21, 22].

This research presents the design development web structure that supports the university sports center manual system to an enhanced automated new system that caters online and easy accessed system. The existed system does not provide recent web structure and lack of online accessed by customers. Thus, a concept of any users can book the sports facilities through the web application and available booking facilities are presented. Users can edit their profile and determined any available date to book the available facilities. The system also provides QR code to the members during their booking. The system's admin task is to check the booking made by the members of the sport facilities and to approve or reject the booking. The administrator also has rights to remove the members and add the member for any rules violations that members do not follow. A new hierarchical web structure is designed and automatic payment generation via online is designed using stripes payment method. This research is significant in presenting how hierarchical web structure is designed and a few booking techniques is guided in QR code, e-mail and webbased booking system concept.

\section{RESEARCH METHOD}

This project aimed to design an online booking web system for sports centre using the content management system (CMS) which also done in previous research [23]. This project used a WordPress platform to build a website system. The system consisted of the login page as an administrator and user as $[24,25]$. The design method presents how sport facilities booking is designed by login credential. After the credential accessed, then a booking page is appeared. Users must click the booking page and select the types of facilities, dates, times and equipment for borrowing processed. Only available timeslot is 
bookable by the users. A calendar as reference is shown in time and date which they booked. Then, the booking is processed, and users will receive an email of confirmation. Approved booking would enable the user to view the detail of the booking and QR code for the reference. Users also can generate the e-ticket from their email. The administrator functions are to monitor and maintain the interface by adding, editing or delete the post. The administrator can control all the system in the website such as remove the member, activate the event and book for the users. Administrator needed a login credential into the system to manage, approve or reject the book. The local server for this system is using Xampp to store the record and the database is retrieved by using phpMyAdmin.

\subsection{Web design structure and process}

This project consisted three-part design process, first is designing the web structure, then registration form and finally generates the ticket. WordPress platform was used to design the website structure for this webbased booking system of a university Sports Centre. Figure 5 shows the overall structure of the website. The web structure separated with two menus which Menu 1 is for users. Menu 2 would appear when user signed in into their account. Figure 6 shows the processes of the registration. The registration process starts with registration form for the new members. The new member needed to pay the registration club fess for three months or one-year subsription. The member can choose a period to become a club member. The payment is designed by using Stripe payment and it is set to use the visa or debit card. After payment has been made, the new member can log in into the page and edit their account or book the facilities.

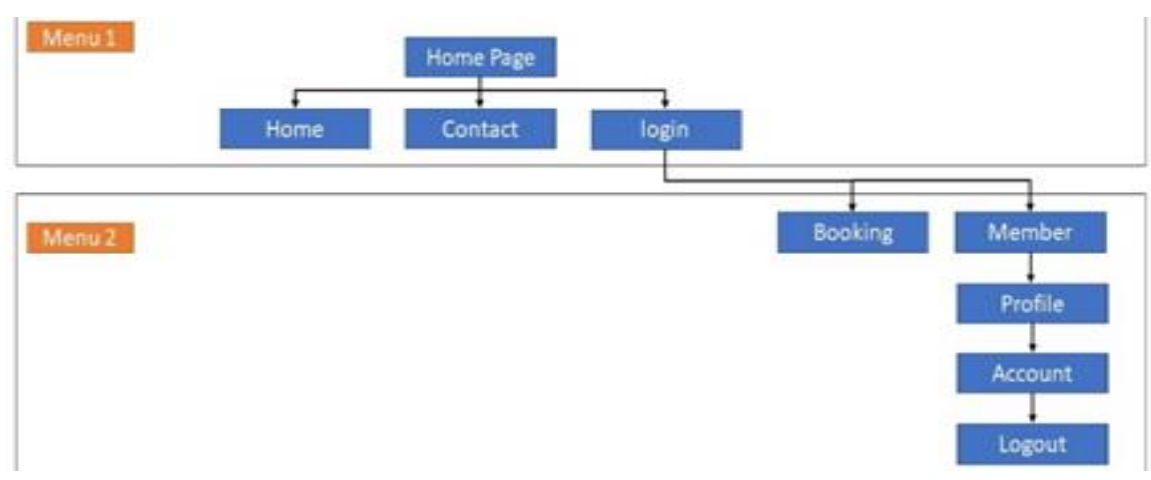

Figure 5. Overall web structure

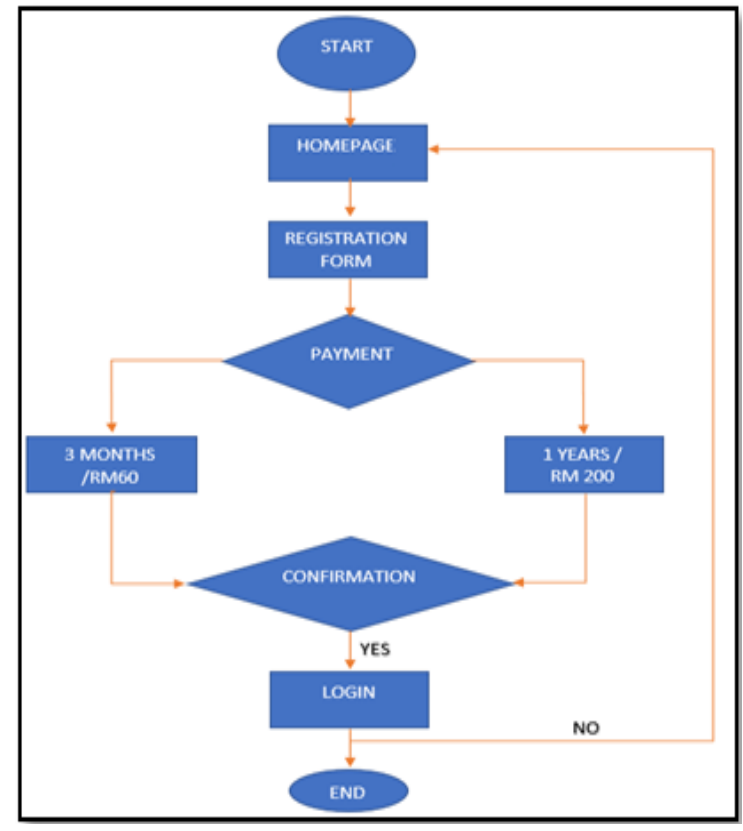

Figure 6. Registration process 


\subsection{E-ticket and parameter design}

Figure 7 shows an e-ticket is generated based on the ID number and email. Member can download the e-ticket or screenshot for reference. Table 1 shows the parameters set to design the structure of Campus Sports Centre System.

Table 1. Parameter design

\begin{tabular}{|c|c|c|}
\hline No & Description & Parameter \\
\hline 1 & Laptop & $\begin{array}{ll}\text { - } & \text { Processor: Intel Pentium 987, Speed 1.5GHz } \\
\text { - } & \text { Chipset: Intel HD Graphics } \\
\text { - } & \text { Displays:15-inch WXGA, LED-backlit display, 1366x768 pixel } \\
\text { - } & \text { RAM: 4GB DDR3 } \\
\text { - } & \text { Hind Disk: } 1000 \text { GB } \\
\end{array}$ \\
\hline 2 & WordPress & - Version 4.8 .1 \\
\hline 3 & Database & - $\quad$ MySQL version 5.0 \\
\hline 4 & PHP & - Version 7.2.5 \\
\hline 5 & Web Server & - $\quad$ Apache/2.433(win32) OpenSSL/1.1.0h PHP/7.2.5 \\
\hline 6 & Server Root & - C: Xampp/htdocs \\
\hline 7 & Security & - Core-LDAP Information Disclosure \\
\hline
\end{tabular}

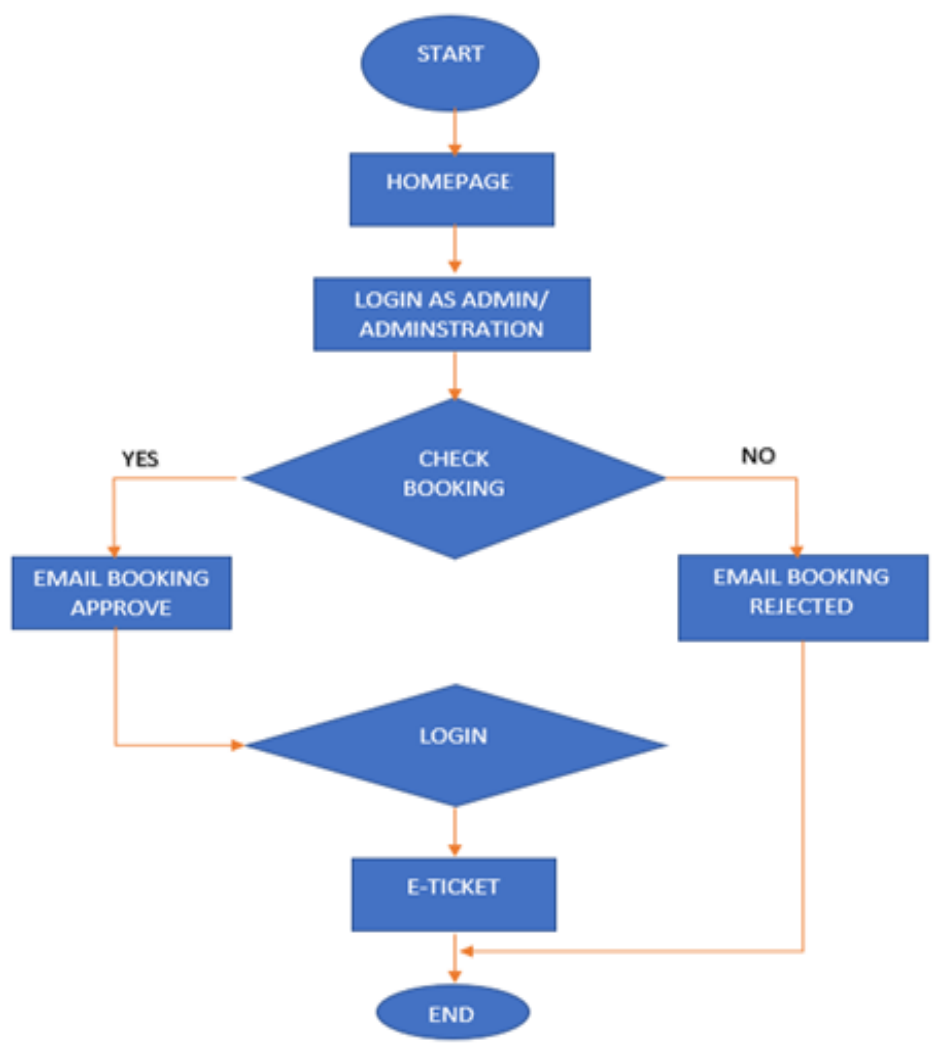

Figure 7. The process to generate E-ticket

\subsection{System development}

The system development comprised of hardware of a web server and website's component files. A domain name is used to monitor and configure a setting that does not require any specific skills and management of hosting settings allows postings website or web page into the Internet. Figure 8 shows software utilization for the current system was developed by CMS using WordPress and the webserver was using XAMPP. These applications are useful powerful, free and open source. The figure shows XAMPP which is a combination of Apache, PHP, and MYSQL where Apache was an HTTP server application to run a dynamic website such as PHP. Apache also includes the MYSQL database and PhpMyAdmin browserbased application for database management. 


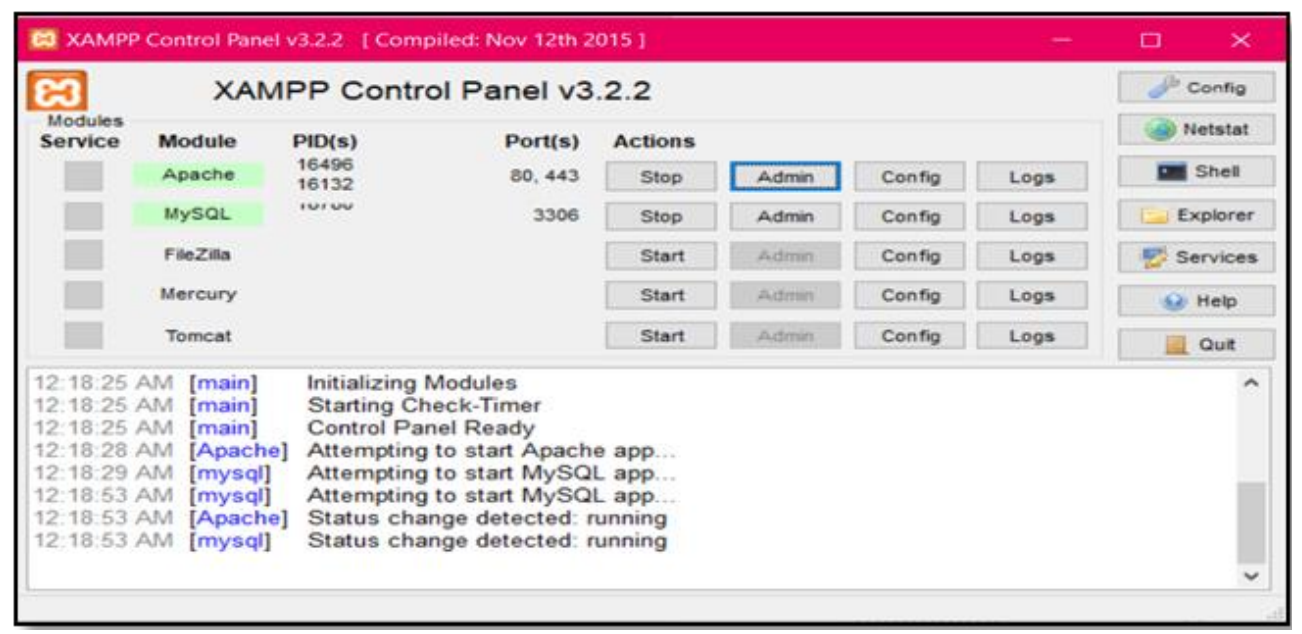

Figure 8. XAMPP server

\section{RESULTS AND DISCUSSION}

\subsection{Website page structure and development}

The website is designed using a hierarchical structure. Figure 9 shows the home page for the users. The page presents a user web interface searches for the Sports Centre on this homepage. The users have to login as users credential and then they are able to view the booking and edit their account page. Figure 10 shows the page after login and when the new members filled the registration form, the new members can view to the fees and had to choose the fees they wanted to pay.
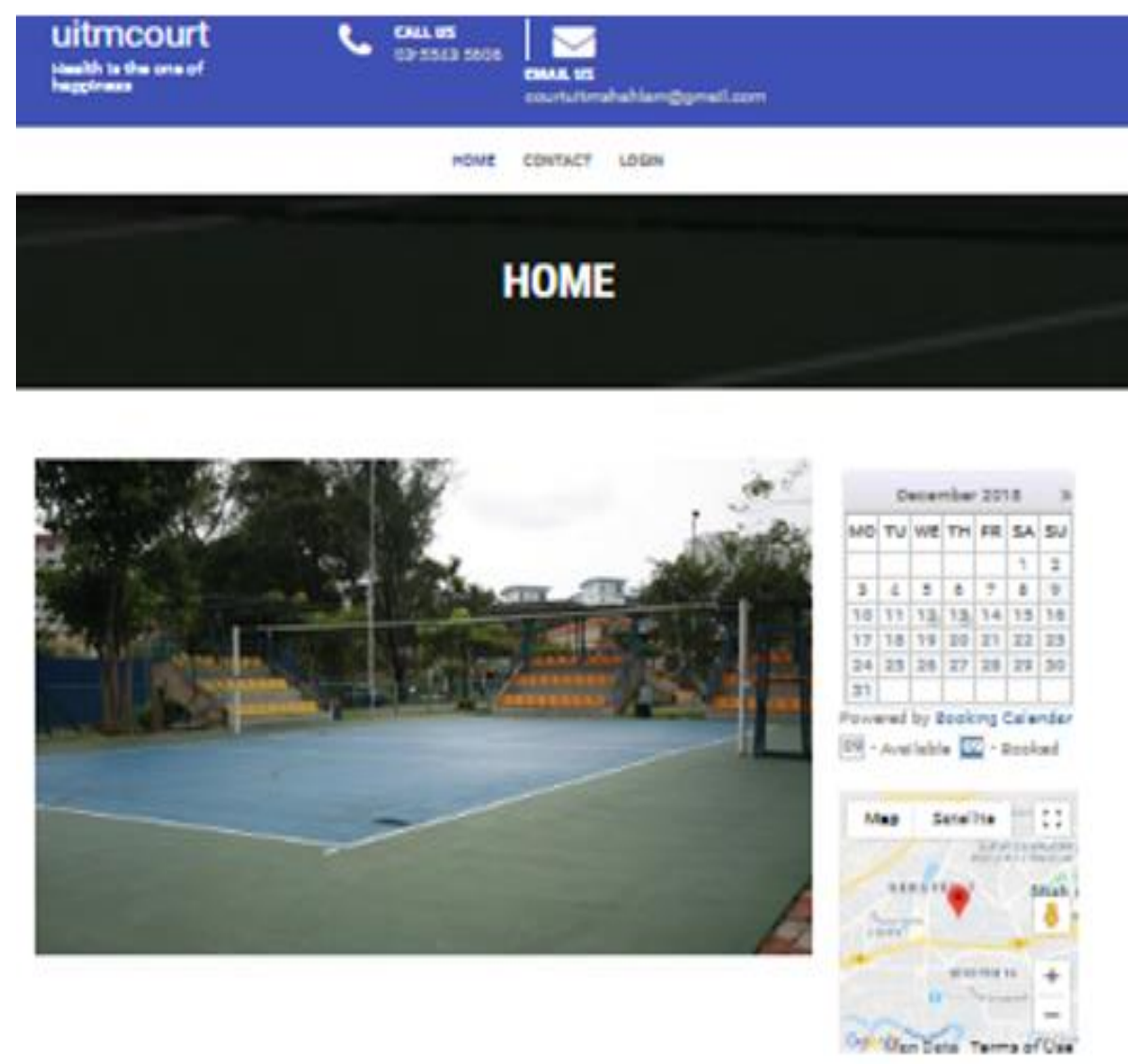

Figure 9. Home page of public sports centre 

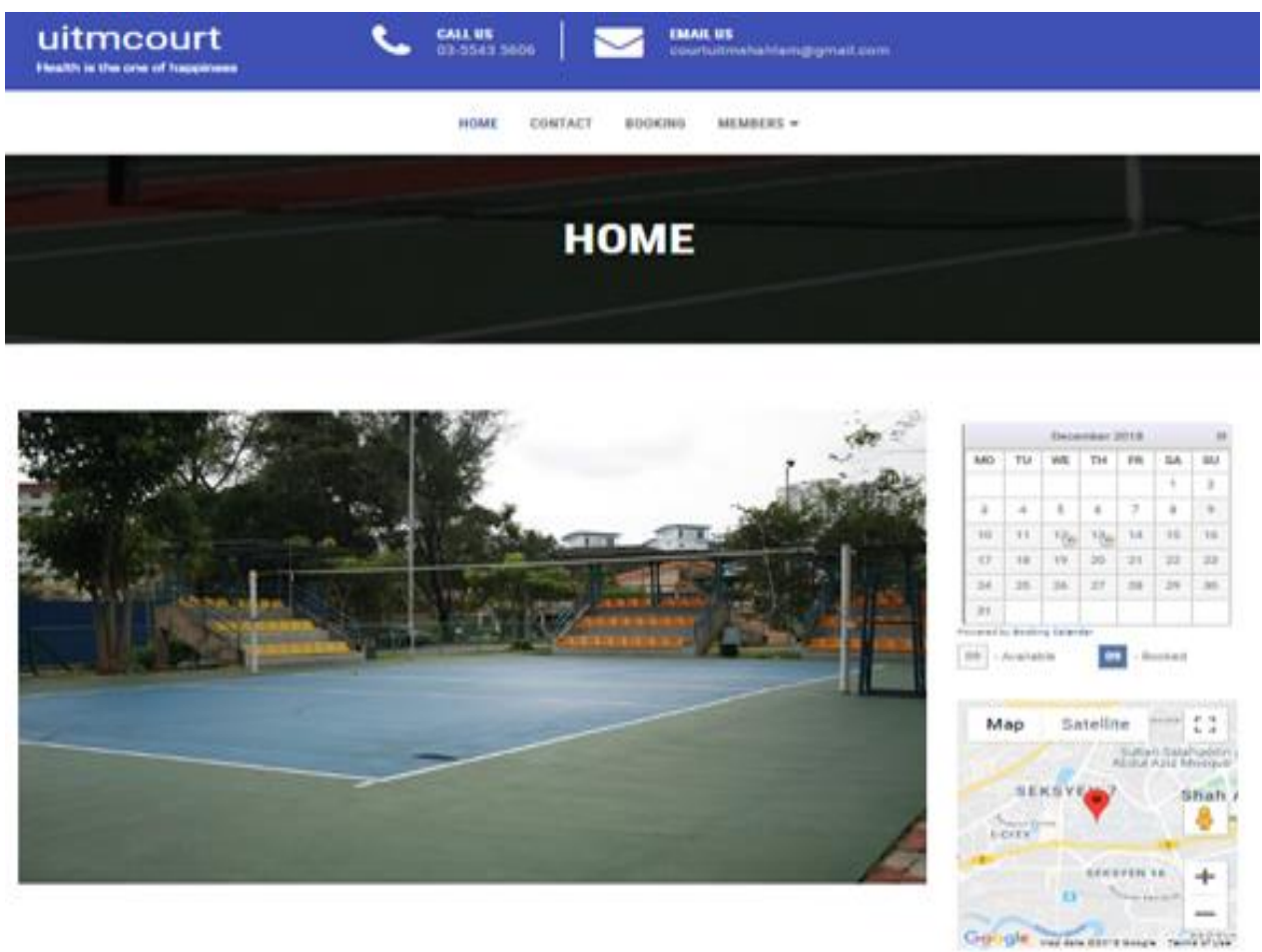

Figure 10. Home page of member sports centre

\subsection{Un-routed structure on the payment page}

The payment page was created for the new members to pay their registration fees to Sport Facilities Management. The fees can be paid by using visa or debit card. The administrator could check the payment from new members from the stripe account. Figure 11 shows the registration page for the fees. Figure 12 shows the Email user gets when their booking was approved by the administration on the e-ticket. If the user wanted to print the ticket the user needs, they have to click them in their email and login based on their email and id number. Figure 13 and 14 shows the page of the print ticket. The system has been tested by samples of student, staff, and outsiders among the sport facilities campus users. Based on the feedback, the system was identified as helpful, easier for them to book the facilities online that presented a new hirachical structure on web.

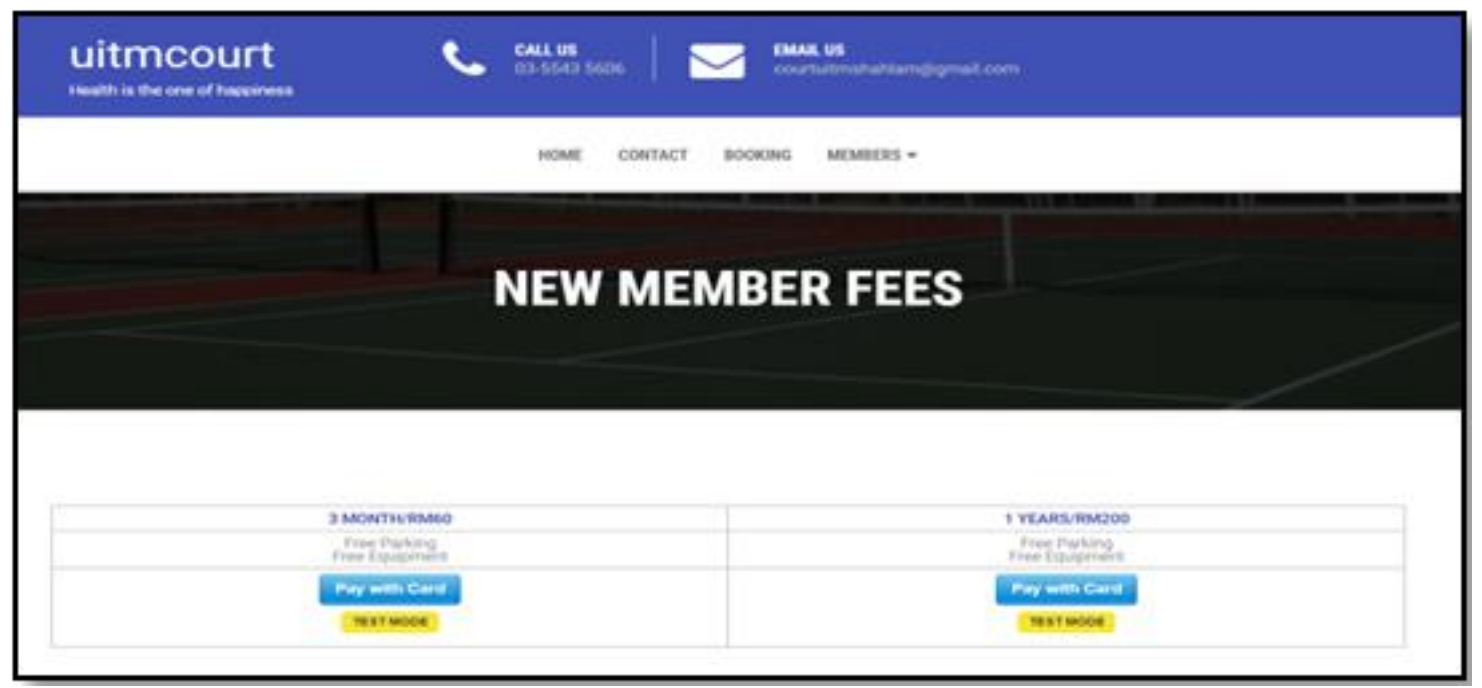

Figure 11. The fees registration page 


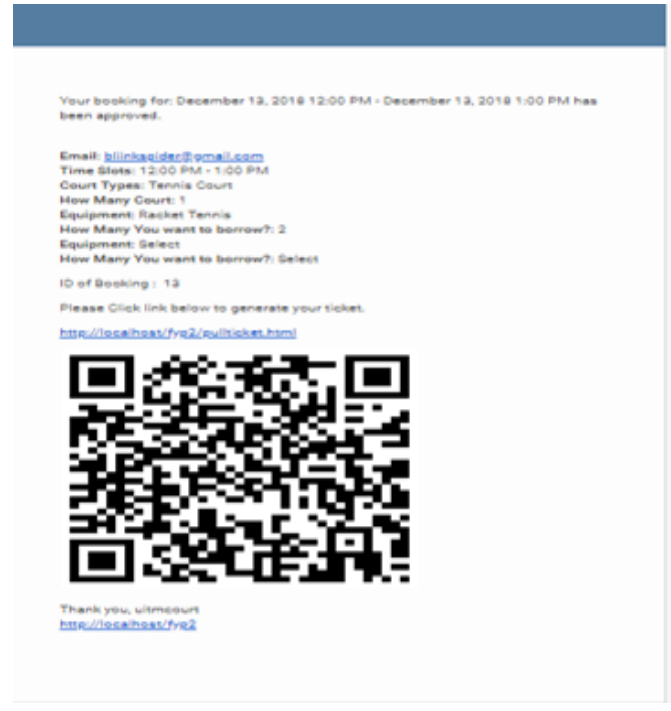

Figure 12. Email approved

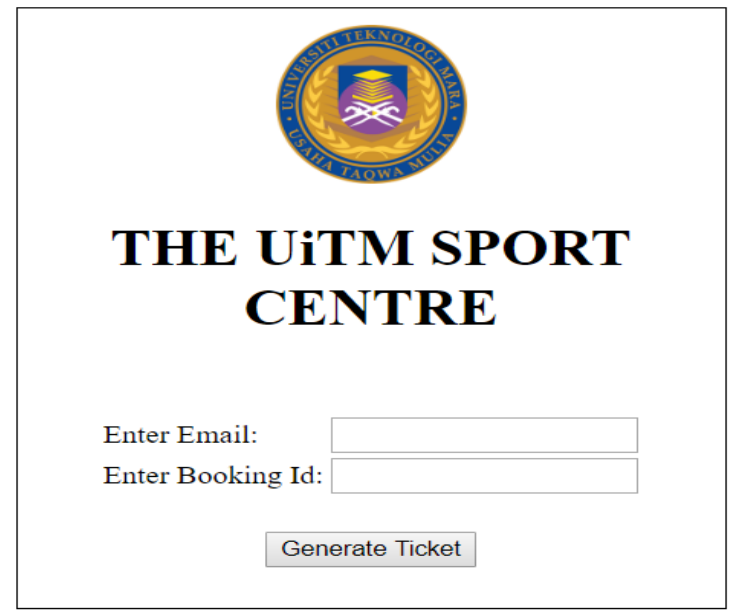

Figure 13. Generate e-ticket

\section{The Court UITM Ticket}

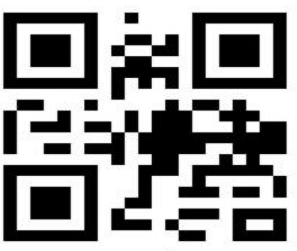

Game Time

2018-12-13 12:00:01

Court:

Tennis Court

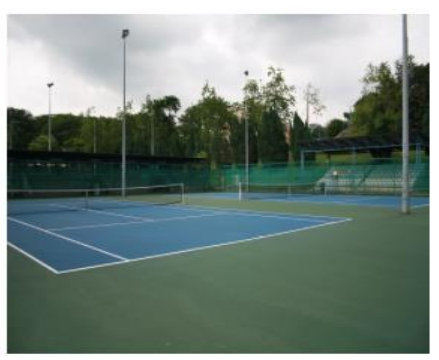

Print Ticket

Figure 14. E-Ticket

\subsection{Analyses on the design development}

Comparison analysis between features of the existing system and the new developed system using the Google form survey has been done. Thirty (30) respondents consist of campus students, staff and communities are taken as samples. Figure 15 shows the number of respondent's book according to the types of members like student, staff, and outsiders. The result shows students did most booking at Campus Sport Centre facilities. Meanwhile, only 6 staffs and 4 outsiders have booked through the development system. Figure 16 shows the different number of respondents uses the Court Centre throughout the years. The highest number of students rented the facilities in the Court Centre were in March, April, September, October, and November. It is identified that the students were registered for their new semester at that time. The result shows that the number of staffs who rented the facilities was decreasing throughout the years. However, the staff and outsiders rented the facilities the most in July and August which is the semester break. 


\section{Types Of Members Vs Number Of Responders}

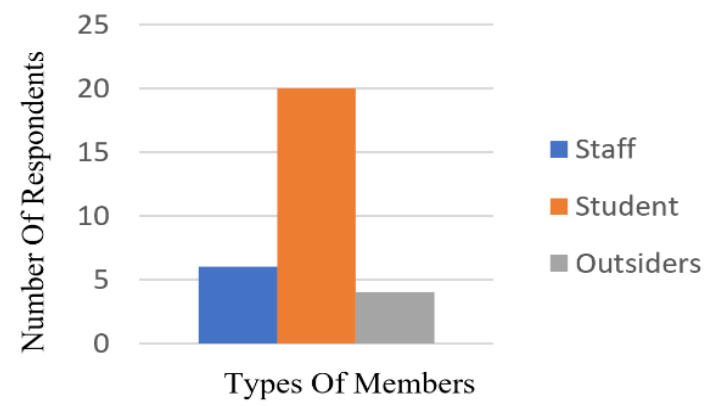

Figure 15. Booking respondents on court system

\section{The Number Of Respondents Use The Sport Centre Throught Year}

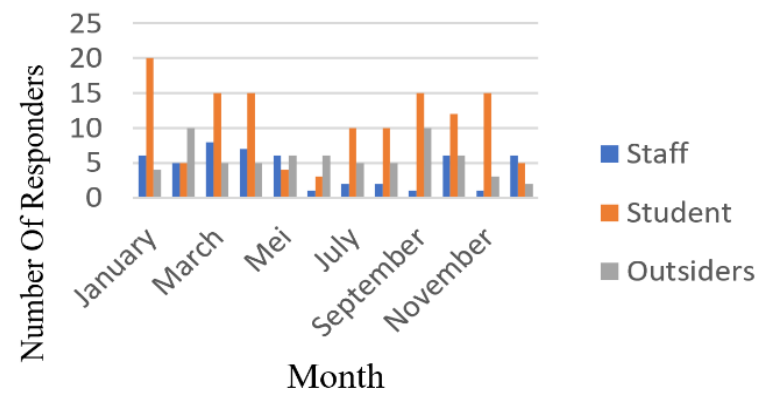

Figure 16. Booking respondents in a year

Figure 17 shows the frequency of the court booking facilities in the Court Centre among the respondents in the Court Centre among the responders in a week. The data was collected throughout the day from morning until night. It shows that most of the members booked the facilities in the evening which is at time 12:00 to 18:00. It is identified that the time was recreational time. Besides, the highest numbers of the members used have recorded in the weekend which was Saturday and Sunday. That was because those days were a public holiday. Figure 18 shows several respondents booking the facilities in Court Centre using different methods. There were three ways provided for the numbers to make their bookings in the existing system. They can book at the counter a day earlier or at the website and just walk in to use the facilities at the counter at the court. The outsiders preferred to book the facilities through the website without having difficulties to be at the sport centre for booking. On the other hand, the students preferred to walk in to use the facilities because they were already in the area. However, most of the staff preferred to book at the counter earlier as they might do not want to take the risks as the existing system, they must check manually the confirmation booking thru website one day before the booking date.

The Frequency of The Booking Facilities

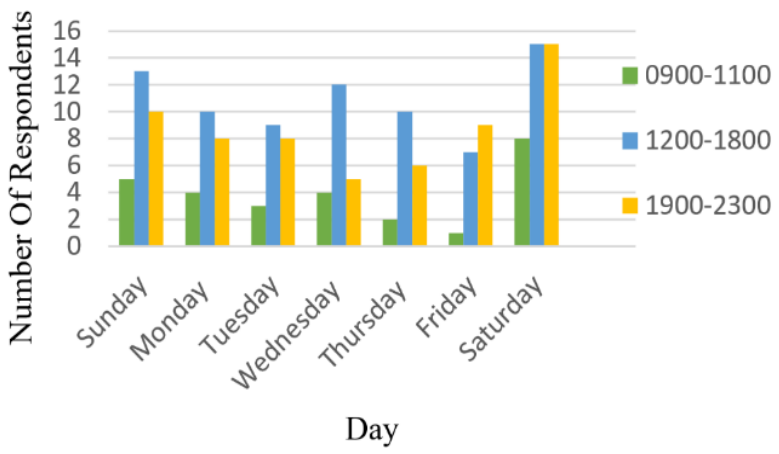

Figure 17. The Frequency of the booking Facilities

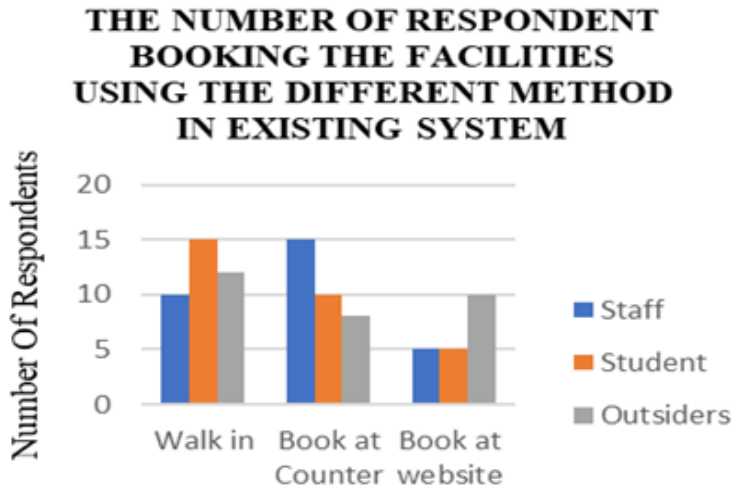

Method Of Booking

Figure 18. Booking respondents vs different method

Figure 19 shows the number of respondents booked the Sport Centre facilities using the new system. The website was the most preferred method by the members to book the facilities at the Court Centre. Instead of walking in and book at the counter. Figure 20 shows the comparison of the methods used by the members to book the facilities at the Sports Centre using the existing system and the new system which has been upgraded. The result shows that they preferred to book on the website when they use the new system. That was because the upgraded version provided friendly user application as they could pay the fees online and get the immediate confirmation from their email without wasting their time to check manually is the existing systems. 


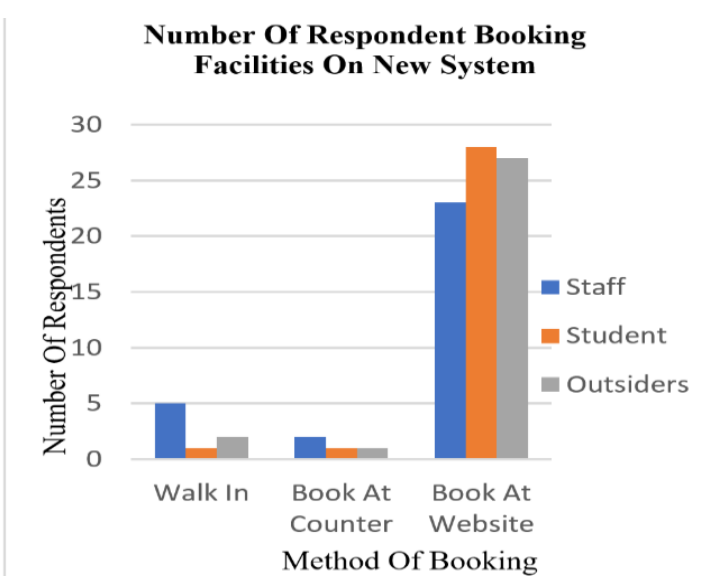

Figure 19. New System Booking Respondents

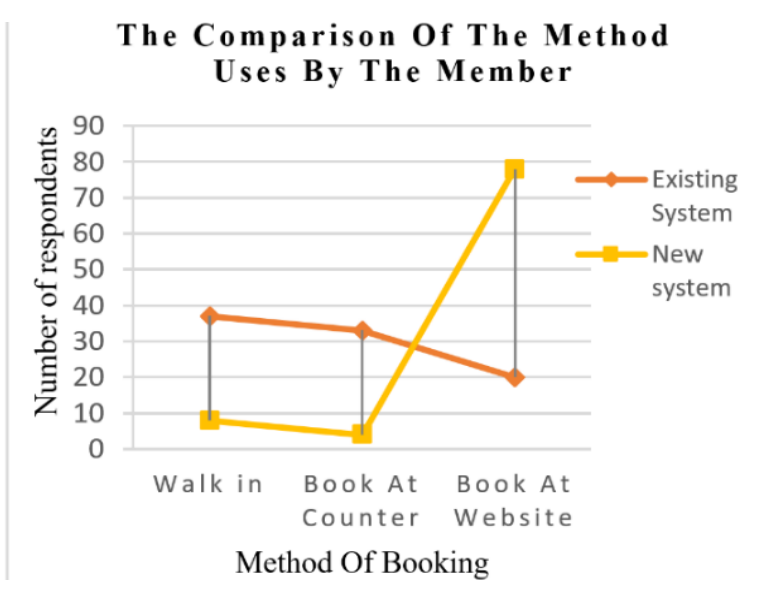

Figure 20. Comparison booking method on the system

\section{CONCLUSION}

The web system for the Sports Centre has been developed and its functionality has been assessed for practical use. A hierarchical web design structure is designed for the web sport centre booking system. The result shows the increases in efficiency of implementing the new features in the web system from $22.22 \%$ to $86.66 \%$ compared to manual system had been implemented in the campus university. The integration with online payment had been observed and evaluated in the stripe payment account. Besides that, the system is dynamic with user friendly user interface and easily application. The system was also could replace the old system which is not convenient to serve the users. The developed system is significant as guidance to support facilities maintenance especially for sport maintenance facilities. The future developed for this system has a wide scope where other sport maintenance facilities needed can be connected and upgraded to the system that supports the update of new technologies which can access through cloud, web and realtime. The system also could be integrated with the hardware for future Internet of Things system and applications to control open and close the tennis court door by designing comprehensive booking system using the mobile application.

\section{ACKNOWLEDGEMENTS}

The author would like to thank the Faculty of Electrical Engineering, Universiti Teknologi MARA, UiTM Shah Alam for the support grant in publishing this paper.

\section{REFERENCES}

[1] G. Kuck, "Tim Berners-Lee's semantic web," SA Journal of Information Management, vol. 6, no. 1, pp, 2004.

[2] S. N. Ibrahim, A. H. Basri, and A. L. Asnawi, "Development of web-based surveillance system for Internet of Things (IoT) application," Bulletin of Electrical Engineering and Informatics, vol. 8, no. 3, pp. 1108-1116, 2019.

[3] A. Rudin, L. Audah, A. Jamil, and J. Abdullah, "Occupancy monitoring system for campus sports facilities using the Internet of Things (IoT)," in 2016 IEEE Conference on Wireless Sensors (ICWiSE), pp. 100-105, 2016.

[4] L. L. Ching, et al., "Smart university: Reservation system with contactless technology," in Proceedings of the Second International Conference on Internet of things, Data and Cloud Computing, p. 9, 2017.

[5] M. H. B. Idris and S. Z. M. Hashim, "UTM sports app mobile application," UTM Computing Proceedings Innovation in Computing Technology and Applications, vol. 2, pp. 1-5, 2017.

[6] M. Kassim, et al., "Web-based student attendance system using RFID technology," in Proceedings - 2012 IEEE Control and System Graduate Research Colloquium, ICSGRC 2012, pp. 213-218, 2012.

[7] J. Kaur and N. Kehar, "RFID enabled cards skimming: enhanced technology," in Proceedings of the International Conference on Advances in Computing and Artificial Intelligence, pp. 155-157, 2011.

[8] M. Shamshiri, C. K. Gan, K. A. Baharin, and M. A. M. Azman, "IoT-based electricity energy monitoring system at Universiti Teknikal Malaysia Melaka," Bulletin of Electrical Engineering and Informatics (BEEI), vol. 8, no. 2, pp. 683-689, 2019.

[9] M. R. L. Perez, A. C. Lagman, and R. T. Adao, "Event management solution using web application platform," in Proceedings of the 2017 International Conference on Information Technology, pp. 206-211, 2017.

[10] L. P. Jie, R. Ramlan, R. Hassan, R. Omar, and C. S. Wei, "Website quality of Malaysian Technical University (MTUN)," Indonesian Journal of Electrical Engineering and Computer Science (IJEECS), vol. 18, no. 3, pp. 1624-1628, 2020. 
[11] M. Kassim and A. Idris, "Multimedia project on website development using dreamweaver and publish domain among engineering students," International E-Journal of Advances in Education, vol. 4, pp. 307-317, 2018.

[12] A. Mirdha, A. Jain, and K. Shah, "Comparative analysis of open source content management systems," in 2014 IEEE International Conference on Computational Intelligence and Computing Research, pp. 1-4, 2014.

[13] M. Kassim, et al., "Self-learning website development through online internet knowledge among engineering students," in 2015 IEEE 7th International Conference on Engineering Education, ICEED 2015, pp. 124-129, 2016.

[14] M. Kassim, et al., "A prototype of web based temperature monitoring system," in ICETC 2010 - 2010 2nd International Conference on Education Technology and Computer, pp. V5266-V5270, 2010.

[15] Z. Chen, et al., "Building a web thesaurus from web link structure," in Proceedings of the 26th annual international ACM SIGIR conference on Research and development in informaion retrieval, pp. 48-55, 2003.

[16] B. Zhou, J. Chen, J. Shi, H. Zhang, and Q. Wu, "Website link structure evaluation and improvement based on user visiting patterns," in Proceedings of the 12th ACM conference on Hypertext and Hypermedia, pp. 241-244, 2001.

[17] A. Islam, "Resort Management System," United International University, 2020.

[18] G. M. Agag, M. A. Khashan, N. Colmekcioglu, A. Almamy, N. S. Alharbi, R. Eid, et al., "Converting hotels website visitors into buyers: How online hotel web assurance seals services decrease consumers' concerns and increase online booking intentions," Information Technology \& People, vol. 33, no. 1, pp. 129-159, 2020.

[19] S. Roy and P. Venkateswaran, "Online payment system using steganography and visual cryptography," in 2014 IEEE Students' Conference on Electrical, Electronics and Computer Science, pp. 1-5, 2014.

[20] K. Aldiabat, "The impact of electronic payment on electronic shopping decision in Jordan," Indonesian Journal of Electrical Engineering and Computer Science (IJEECS), vol. 14, no. 2, pp. 1018-1024, 2019.

[21] W. O. Aly, "The institutional layering arrangements of the Egyptian government's e-payment system: An analytical case study," Journal of Payments Strategy \& Systems, vol. 14, no. 1, pp. 61-74, 2020.

[22] N. A. Sulaiman and M. Kassim, "Developing a customized software engineering testing for shared banking services (SBS) System," in Proceedings - 2011 IEEE International Conference on System Engineering and Technology, ICSET 2011, pp. 132-137, 2011.

[23] A. Toding, K. Shankar, E. L. Lydia, M. Huda, and S. Abadi, "A framework for content management system for effectiveness of web applications," TEST Engineering \& Management, vol. 82, pp. 4961-4967, 2020.

[24] Z. M. Assaf, "How to build a website using wordpress," US: CreateSpace Independent Publishing Platform, 2015.

[25] J. Rodas-Silva, et al., "Selection of software product line implementation components using recommender systems: An application to Wordpress," IEEE Access, vol. 7, pp. 69226-69245, 2019.

\section{BIOGRAPHIES OF AUTHORS}

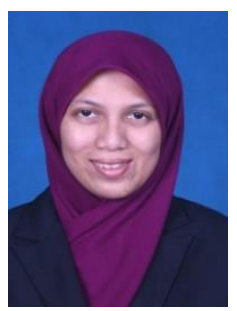

Nor Sajidah Ab Ghani is a student in Master of Science in Telecommunication and Information Engineering in 2019 at Faculty of Electrical Engineering, Universiti Technologi MARA, UiTM Shah Alam, Selangor, Malaysia. Her study focuses on the web developer and network. Her motivation is to try a greater challenge with a solid college utilizing the opportunity to offer proven and developing skills in research related to Web development and computer engineering area.

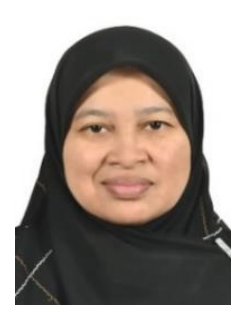

Murizah Kassim is currently working as Associate Professor at Faculty of Electrical Engineering, Universiti Teknologi MARA, Shah Alam, Selangor. She received her PhD in Electronic, Electrical and System Engineering in 2016 from the Faculty of Built Environment and Engineering, Universiti Kebangsaan Malaysia (UKM). She has published many indexed papers related to computer network, IoT, Web and Mobile development applications research. She experienced for 19 years in the technical team at the Centre for Integrated Information System, UiTM. She is also head of Enabling Internet of Things Technologies (ElIoTT) research group UiTM. She joined the academic since January 2009 and currently member of MBOT, IEEE, IET, IAENG and IACSIT organization.

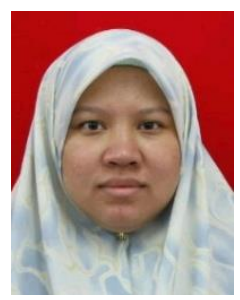

Aziati Husna Awang is currently working as senior lecturer in Malaysia at Faculty of Electrical Engineering, Universiti Teknologi MARA, Shah Alam, Selangor. She received her Bachelor's Degree (hons) in Electrical and Electronic Engineering from UNITEN in 2001 and MSc degree from Bradford University in 2004. She obtained her Doctoral Degree in Electronic Engineering from Leeds University in 2013. She has published a numbers of indexed conference papers and international journal. Her research interest includes the wireless technology, IOT, Photonics and Microwave technologies. 